\title{
Xanthine Oxidase Inhibitory Activity and Antigout of Celery Leek Parsley and Molokhia
}

\author{
Hanaa S. M. Abd El-Rahman ${ }^{1}$, Nasra A. M. Abd-ELHak ${ }^{2}$ \\ ${ }^{1}$ Special Food and Nutrition Dept., Food Technology Research Institute, Agric. Res. Center, Giza, Egypt \\ ${ }^{2}$ Kitchen Experimental Unit, Food Technology Research Institute, Agric. Res. Center, Giza, Egypt \\ Email address: \\ Hanaasayed97@yahoo.com (H. S. M. A. El-Rahman), dr.nasraahmed@yahoo.com (N. A. M. Abd-ELHak)
}

\section{To cite this article:}

Hanaa S. M. Abd El-Rahman, Nasra A. M. Abd-ELHak. Xanthine Oxidase Inhibitory Activity and Antigout of Celery Leek Parsley and Molokhia. Advances in Biochemistry. Vol. 3, No. 4, 2015, pp. 40-50. doi: 10.11648/j.ab.20150304.11

\begin{abstract}
The present study was aimed at investigating in vitro xanthine oxidase inhibitory (XOI) and in vivo antigout activity extracts of celery, leek, parsley, and molokhia. The degree of XO inhibitory activity was determined by measuring the absorbance spectrophotometrically at $295 \mathrm{~nm}$, which is associated with uric acid formation which is linked to gout. Our preliminary screening study had employed the use of distilled water, and absolute ethanol to determine XOI from celery, leek, parsley, and molokhia. In general, our study showed that the ethanolic extracts were found to be more active than the aqueous extracts. Further in-vivo antigout was studied gout induced in rats by potassium oxonate. A total of 36 male albino rats were randomly divided into 6 equal groups. Group 1 negative control given only standard diet, and group 2-6 given Potassium oxonic acid $(250 \mathrm{mg} / \mathrm{kg}$, i.p.), Potassium oxonate an uricase inhibitor was used to induce gout. Oral administration (G3, G4, and G5) of celery, leek, parsley (5 g/Kg), and (G6) molokhia $(4.8 \mathrm{~g} / \mathrm{Kg})$ showed a significant decrease in uric acid, and Creatinine levels in the gouty rats. All extracts (celery, leek, parsley, and molokhia) have shown significant decrease in level of Malonaldehyde (MDA) and increase in activity of antioxidant enzyme level, comparable to positive rat (G2). No significant changes between all extracts used and negative control in gain weights and organic phosphorus was noticed. The results showed that increasing serum total calcium level with extracts of celery, leek, parsley, and molokhia in comparison to positive control. The celery, leek, parsley, and molokhia extracts have some protective effects on the gout.
\end{abstract}

Keywords: Celery, Leek, Parsley, Molokhia, Gout, Xanthine Oxidase Inhibitory

\section{Introduction}

Gout is a multi-factorial disease affecting the flexibility of joints. It is usually characterized by re-current attacks of acute inflammatory arthritis-a red, tender, hot, swollen joints leading to bursitis (1). It is a serious disease that has been growing in prevalence during the past several years in Western civilizations (2). Gout is characterized by abnormally high levels of uric acid in the body, resulting in the formation and deposition of urate (as monosodium uratemonohydrate) crystals, generally known as tophi crystals in joints, tendons and surrounding tissues, characterized by hyper-uricemia and in chronic stage, may lead to renal failure(3). These crystals cause an acute inflammatory response and can induce a permanent tissue damage which is characterized by the appearance of ulceration of the joint cartilage, marginal osteophytosis, geodic and erosive lesions and chronic inflammation of synovial membrane (4 and
5).This is partly a reflection of changes in diet, increases in longevity, hypertension, metabolic syndrome, and advanced renal disease, and the broad use of diuretics in clinical practice. Management of gout in the elderly, in organ transplant recipients, and in patients with renal insufficiency and allopurinol intolerance can be particularly challenging (6).Uric acid is the end product of purine metabolism in humans, and its overproduction by xanthine oxidase (XOD) from purine compounds or under excretion can lead to hyperuricemia as gout. Enzymatic degradation of hypoxanthine and xanthine leads to the production of uric acid (7 and 8). The major site of purine synthesis is in the liver. The synthesis of uric acid occurs along two pathways, referred to as the de novo and the salvage pathways. Synthesis of the purine nucleotides begins with the formation of phosphoribosyl pyrophosphate (PRPP) by PRPP synthetase and leads to the first fully formed nucleotide, inosine 5'-monophosphate (IMP). IMP is converted into either adenosine 5'-monophosphate (AMP) or guanosine 5'- 
monophosphate (GMP) through two distinct reaction pathways. Catabolism of the purine nucleotides leads

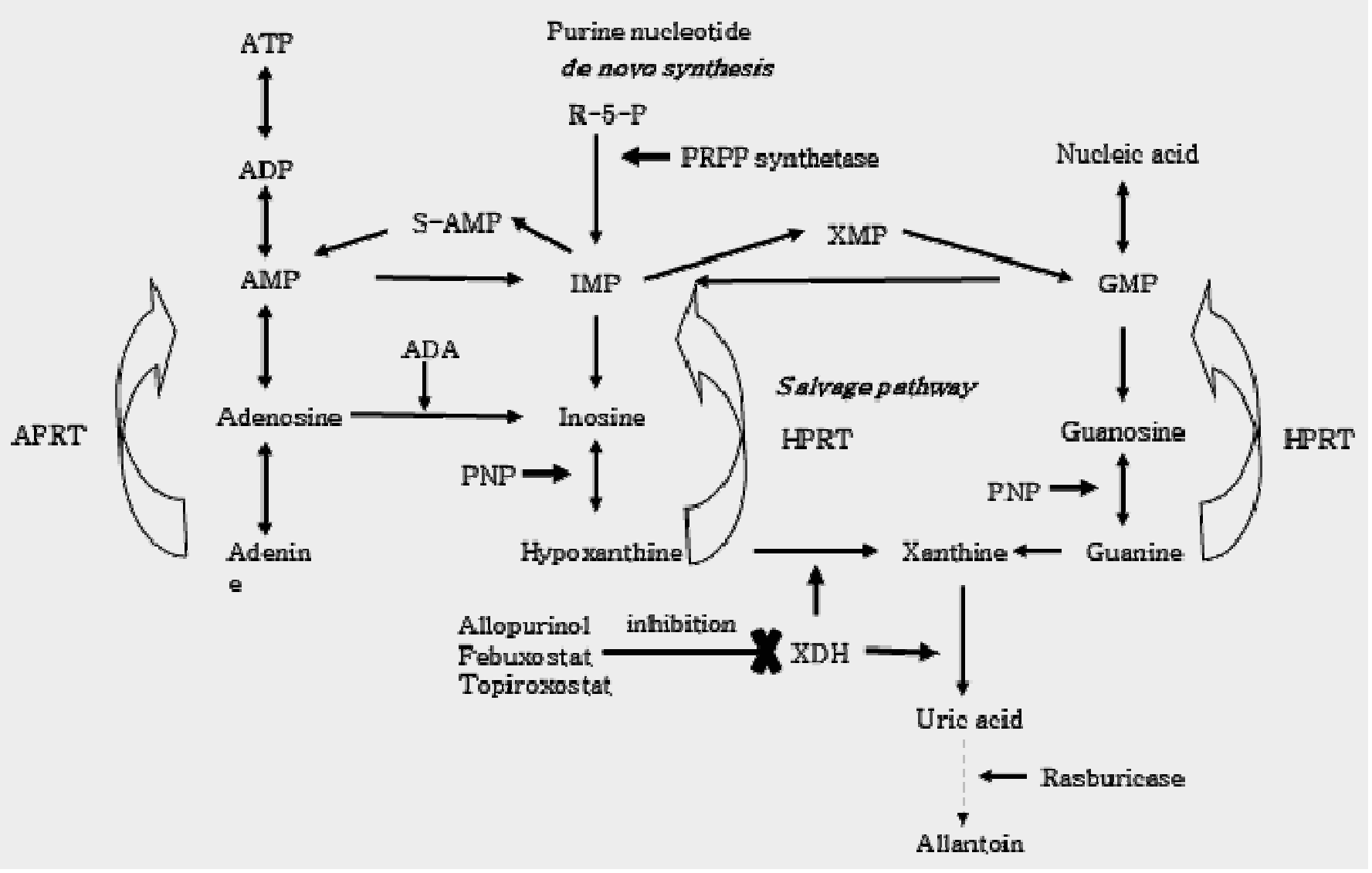

Abbreviations: ADA, adenosine deaminase; APRT, adenosine phosphoribosyl transferase; HPRT, hypoxanthine phosphoribosyl transferase; PNP, purine nucleoside phosphorylase; $\mathrm{XDH}$, xanthine dehydrogenase

Fig. (1). Purine metabolic pathway in humans.

XOD (EC 1.17.3.2) is a rate-limiting enzyme in the biosynthesis of uric acid and catalyzes the oxidation of hypoxanthine and xanthine to uric acid (8), which is responsible for the medical condition leading to painful inflammation called gout (10). XOD is distributed most abundantly in the liver and intestine (11), situated at the end of a catabolic sequence of the purine nucleotide metabolism in humans and few other uric species (12). XOD also serves as an important biological source of oxygen-derived free radicals that contribute to oxidative damage to living tissues involved in many pathological processes such as inflammation, atherosclerosis, and cancer. In-vitro bioassays are used to examine test material for XOD inhibition, as inhibitors of XOD may be potentially useful for the treatment of gout or other XOD induced diseases (13). Therefore, XOD inhibitors can be potent therapeutic agents for the prevention of hyperuricemia by inhibition of uric acid biosynthesis (12). The treatment of gout entails the use of the therapeutic agents such as xanthine oxidase inhibitors (XOI) (14 and 12). XOI acts by blocking the biosynthesis of uric acid from purine in the body (12) and it is believed that either by increasing the excretion of uric acid or reducing the uric acid production helps to reduce the risk of gout (15).Current treatments to gout includes Nonsteroidal anti-inflammatory drugs (NSAIDS) such as ibuprofen, naproxen, indomethacin, aspirin, etoricoxib (cox-2 selective inhibitors); corticosteroids such as prednisone; allopurinol, probencid, colchicines (to decrease severity of episodes). Although these agents are generally effective, they generates superoxide (16) and lead to several side effects such as skin allergies, fever, rash and diarrhoea progressively developing leukocytosis, eosinophilia, vasculitis, aseptic meningitis, nephritis and renal dysfunction, and hepatic dysfunction (17 and 18). Allopurinol is an XOD inhibitor used clinically for the treatment of gout. However, it can have side effects, such as hypersensitivity reaction, Stevens - Johnson syndrome, renal toxicity, and even fatal liver necrosis (19). So, there is a need of herbal extracts with antioxidant property to nullify oxidative and inflammatory response produced by xanthine oxidase. It is believed that XOD inhibitors from natural sources can be used as alternatives to allopurinol because of fewer potential adverse side effects (20). Some tropical plants and their phytochemicals are worth to be explored as potential XOI as they are already used as food or food supplements for many years and found safe for 
human bodies (21). Polyphenols, flavonoids, coumarins, ellagic acid, and valoneic acid dilactone (VAD) have been reported to be potent plant-based XOI $(22 ; 23 ; 24 ; 25$ and 12).

Celery (Apium graveolers dulce) is a biennial plant, belongs to the Umbelliferae family. The celery plant cultivated in the Mediterranean region and its Arabic name is Karafs. Celery seeds contain several substances including volatile oils; flavonoids, antioxidants that give plants their colors and may protect cells from damage; coumarins, chemicals that help thin the blood; and linoleic acid, an omega- 6 fatty acid. Celery seed is used for treating arthritis and gout, and to help reduce muscle spasms, calm the nerves, and reduce inflammation (26 and 27). Leeks (Allium porrum or A. ampeloprasumvar. porrum), sometimes called "the gourmet's onion". The thick leaf bases and slightly developed bulb look like a giant green onion, and are eaten as a fresh vegetable. Leeks contain saponins and the major flavonoid in leeks is kaempferol, with only a small amount of quercetin, carotenoids and chlorophyll mainly in the green tops(28 and 29).Parsley (Petroselinum crispum) is a member of Apiaceous family that has been employed in the food, pharmaceutical, perfume, and cosmetic industries (30). In folk medicine, parsley is used to treat a wide variety of conditions (31). Phytochemical screening of parsley has revealed the presence of several classes of flavonoids (32). Flavonols (kaempferol and quercetin) and flavones (apigenin and luteolin), which occur as glycosidic form in nature, are major flavonoids found in parsley (33).

Molokhia Corchorus olitorius (Tiliaceae) is an annual herb whose leaves and roots are used as herbal medicine and eaten as vegetable by local people in East Malaysia, India, Egypt, and Philippines (34).Traditionally, its leaves are used in the treatment of pain, fever, chronic cystitis and tumors (35). Molokhia abundantly contains 5-caffeoylquinic acid, 3, 5dicaffeoylquinic acid, quercetin 3-galactoside, quercetin3glucoside, quercetin 3-(6-malonylglucoside), quercetin3(malonylgalactoside), ascorbic acid, $\alpha$-tocopherol, and chlorophyll, etc., and the content of quercetin glycosidesis remarkable (36).

Therefore, the present study was carried out to evaluate the xanthine oxidase inhibitory potential of some plants (celery, leek, parsley, and molokhia) and in vivo anti-inflammatory in experimental gout model in rats.

\section{Materials and Methods}

\subsection{Reagents and Chemicals}

Potassium oxonate, allopurinol, xanthine and xanthine oxidase (buttermilk) were purchased from Sigma-Aldrich Chemicals (St. Louis, MO, USA). Dimethylsulphoxide (DMSO), hydrochloric acid ( $\mathrm{HCl})$, absolute ethanol, and other reagents of analytical grade were obtained from Merck (Darmstadt, FR, Germany). Potassium di-hydrogen phosphate $\left(\mathrm{KH}_{2} \mathrm{PO}_{4}\right)$ and dipotassium hydrogen phosphate
$\left(\mathrm{K}_{2} \mathrm{HPO}_{4}\right)$ were of the highest purity. All other reagents were purchased from Merck (Darmstadt, Germany). The reagents used were from of analytical grades.

\subsection{In-Vitro Xanthine Oxidase Inhibitory Activity}

\subsubsection{Preparation of Crude Extracts}

The plants were washed and oven-dried for $72 \mathrm{~h}$ at $40^{\circ} \mathrm{C}$. The dried plant materials were grounded using domestic blender to small particle size. All plant materials were subjected to a standard procedure of solvent extraction process (37). $1 \mathrm{~g}$ of each of the dried powdered plant material was added into $10 \mathrm{ml}$ of extraction solvent and all experiments were conducted in triplicate. Two extraction solvents were employed, namely, absolute ethanol and distilled water. The mixture of the ground sample and solvent were capped with aluminum foil, and placed in an incubator shaker. The agitation speed of the incubator shaker was set at $100 \mathrm{rpm}$ and ran for $6 \mathrm{~h}$ at $30^{\circ} \mathrm{C}$. Each mixture of plant material and extraction solvent was filtered using Whatman No. 1 filter paper and the filtrate was collected, concentrated by vacuum rotary evaporator and dissolved in Di-Methyl Sulfoxide (DMSO) (100\%). Then, it was subjected to XO inhibitory activity assay spectrophotometrically at $295 \mathrm{~nm}$ to determine the XOI properties.

\subsubsection{Xanthine Oxidase Inhibitory Activity Assay}

The crude extract was used for the analysis of XO inhibition under in vitro assays. The inhibitory effect on XO was measured spectrophotometrically at $295 \mathrm{~nm}$ under aerobic condition, with some modifications, following the method reported by Unno et al., (12) and Umamaheswari et al., (15). A well-known XOI, allopurinol $(100 \mu \mathrm{g} / \mathrm{ml})$ was used as a positive control for the inhibition test. The reaction mixture consisted of $300 \mu \mathrm{l}$ of $50 \mathrm{mM}$ sodium phosphate buffer $(\mathrm{pH}$ 7.5), $100 \mu \mathrm{l}$ of sample solution dissolved in DMSO $100 \mu \mathrm{l}$ of freshly prepared enzyme solution $(0.2$ units $/ \mathrm{ml}$ of xanthine oxidase in phosphate buffer) and $100 \mu \mathrm{l}$ of distilled water. The assay mixture was pre-incubated at $37^{\circ} \mathrm{C}$ for $15 \mathrm{~min}$. Then, $200 \mu$ of substrate solution $(0.15 \mathrm{mM}$ of xanthine) was added into the mixture. The mixture was incubated at $37^{\circ} \mathrm{C}$ for 30 min. Next, the reaction was stopped with the addition of $200 \mu \mathrm{l}$ of $0.5 \mathrm{M} \mathrm{HCl}$. The absorbance was measured using UV/VIS spectrophotometer against a blank prepared in the same way but the enzyme solution was replaced with the phosphate buffer. Another reaction mixture was prepared (control) having $100 \mu \mathrm{l}$ of DMSO instead of test compounds in order to have maximum uric acid formation. The equation reported by Naseem et al., (38) was used to evaluate the degree of XO inhibitory activity. Thus, XOI activity was calculated using Eq.1, in which $\alpha$ is the activity of XO without test extract and $\beta$ is the activity of $\mathrm{XO}$ with test extract. $\% \mathrm{XO}$ inhibition $=(1$ $-\beta / \alpha) \times 100(1)$

\subsection{In-Vivo Antigout Activity}

\subsubsection{Preparation of Extract}

The edible portions of fresh plant (celery, leek, parsley, and molokhia) which were purchased from local markets in 
Cairo, Egypt. Celery, Leeks, and Parsley, leaves were carefully washed with water and left to dry at room temperature. Then they were weighted and completely blended in distilled water (1: $1 \mathrm{w} / \mathrm{v})$ (39). Aqueous extract of molokhia were washed with water and dried (solar drying), they were weighted and completely blended in distilled water and boiling for $10 \mathrm{~min}$. The extract was filtered to remove particulate matters, and then administered orally to rats at dose of $4.8 \mathrm{mg} / \mathrm{kg}$ body weight (40 and 41). All freshly prepared juicy samples were administrated to the corresponding groups by oral gavage once a day for 4 weeks.

\subsubsection{Animals}

A total of 36 male albino rats (body weights: 160-205 g) were used in the present study. The rats were kept under normal health laboratory conditions and fed on basal diet for one week. Water and basal diet were provided ad libitum for 30 days. All the experimental procedures were carried out in the Ophthalmology Research Institute, Giza, Egypt. The animals were observed daily for any signs of toxicity. Body weight was recorded at regular intervals throughout the experimental period.

\subsubsection{Animal Model of Gout in Rats}

Experimentally-induced gout in rats (due to inhibition of uricase with potassium oxonate) was used to study antigout (42). Briefly, $250 \mathrm{mg} / \mathrm{Kg}$, uricase inhibitor, potassium oxonate (PO), dissolved in $0.9 \%$ saline solution was administrated intraperitoneally to each animal except group 1 (group 2-6), $1 \mathrm{~h}$ before oral administration of test juicy samples.

\subsubsection{Experimental Design}

Animals were divided into 6 groups of six rats each. Group 1 served as the normal control (negative control). Group 2 served as gouty control (positive control). Group 3, 4, 5, (gouty rats) received celery, leek, and parsley at the oral dose of $5 \mathrm{~g} / \mathrm{Kg}$ extract (39). Group 6 (gouty rats) received extract of molokhia at the oral dose of $4.8 \mathrm{~g} / \mathrm{Kg}$ (41).

\subsubsection{Biochemical Evaluation}

At the end of the treatment period, rats were weighed. All animals were fasted for $12 \mathrm{~h}$, and then blood samples were collected from the animal's eye plexus under diethyl ether anesthesia. Serums were separated out by centrifugation at $3000 \mathrm{rpm}$ for $15 \mathrm{~min}$. After the collections of blood samples, animals were killed. Lipid peroxidation in plasma was estimated by the method of Ledwozy et al., (43). Malonaldehyde (MDA) produced during peroxidation of lipids served as an index of lipid peroxidation. MDA reacts with TBA to generate a colour product, which absorbs at $532 \mathrm{~nm}$. Superoxide dismutase (SOD) activity was determined by the method of Marklund and Marklund (44)). The degree of inhibition of the auto-oxidation of pyrogallol at an alkaline $\mathrm{pH}$ by SOD was used as a measure of the enzyme activity. Catalase and Glutathione peroxidase activities were estimated by the method of Sinha (45) and Rotruck et al., (46). The activity of Catalase was expressed as $\mu \mathrm{g}$ of $\mathrm{H}_{2} \mathrm{O}_{2}$ consumed $/ \mathrm{mn} / \mathrm{mg}$ protein. Glutathione peroxidase was expressed as $\mu \mathrm{g}$ of glutathione utilized /minute/mg/ protein. The activity of acid phosphatase was assayed by the method of King (47).Alkaline phosphatase (ALP; EC 3.1.3.1) activity was measured at $405 \mathrm{~nm}$ by the formation of para-nitrophenol from para nitrophenylphosphate as a substrate using the method of Varley et al., (48). Creatinine, and uric acid were determined by using the methods described by Larsen (49) and Caraway (50), total protein content was measured by the method of Lowry et al., (51). Total calcium and organic phosphourus was measured by the method of Ferguson et al., (52) and Fiske and Subbarow (53).

\subsection{Statistical Analysis}

The resulted data were subjected to statistical analysis using the standard analysis of variance (one-way ANOVA) as outlined by Snedecor and Cochran (54).and the differences among means dose of all extracts effects were tested for the least significance difference value (LSD) at 0.05 probabilities by using Duncan's multiple range tests by SPSS for Windows statistical package, version 10.0.

\section{Results}

\subsection{In-Vitro Xanthine Oxidase Inhibitory Activity}

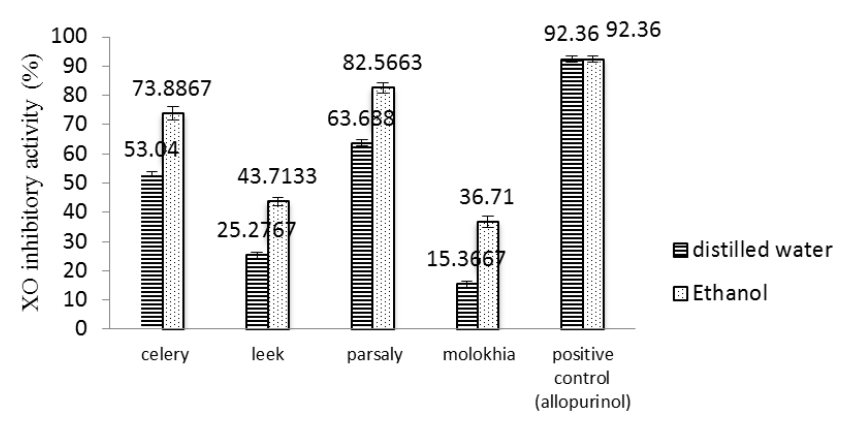

Fig. (2). XO inhibitory activity (\%) of extracts of celery, leek, parsaly, and molokhia using absolute ethanol and distilled water as the extraction solvent.

The effectiveness of selected extraction solvents to extract bioactive compounds responsible for XO inhibitory activity was studied. The percentages of XO inhibitory activity of all crude extracts obtained by using distilled water and absolute ethanol were in figure 2. The comparison was also made between the plant extracts in two extraction solvents and the positive control (allopurinol), to determine the best extraction solvent. In general, the ethanol extracts were found to be more active than the aqueous extracts. The highest XOI activity was shown by ethanol extract both of parsley and celery with $82.5663 \%$ and $73.8867 \%$, respectively. While, the lowest value were $15.3667 \%$ and $25.2767 \%$ for aqueous extract of molokhia and leek, respectively. The results were compared with the standard drug allopurinol, which showed 


\section{$90.36 \%$ inhibition.}

\subsection{In-Vivo Anti-Gout Activity}

The ability of extracts (celery, leek, parsley, and molokhia) to inhibit uricase was investigated in this study. In the present study, no significant changes had been observed in gain weights (\%) of the treated groups as compared with controls (Table 1). Administration of uricase inhibitor, potassium oxonate significantly affected various bio-chemical parameters on rat blood. As shown in Table 1, an increase was in the serum uric acid and creatinine levels in positive control (G2) when compared to the negative control (G1). Extracts of Leek (G4) and parsley (G5), significantly $(p<0.05)$ reduce serum uric acid levels of gouty rats to values than that found in $\mathrm{G} 2$.

Administration of aqueous extract of molokhia at a dose of $4.8 \mathrm{~g} / \mathrm{kg}$ was effectively reduced serum creatinine levels in rat compared to the gouty rat groups (G3, G4, G5), though still higher than the normal control level (G1).

As shown in Figure 3, significant decrease in serum total calcium concentrations in G2. No significant changes were observed in extracts of parsley (G5), molokhia (G6), and negative control (G1).

Oral administration extracts of celery, leek, parsley, and molokhia significantly reduced $(\mathrm{p}<0.05)$ the serum organic phosphorus levels of gouty rats but not positive control (G2). The results also indicate that no significantly changes between all extracts used and negative control (Figure 4).

Table 1. Effect of the orally administered of celery, leek, parsely, and molokhia on serum uric acid, creatinine, and gain weight in potassium oxonate -induced rat.

\begin{tabular}{llll}
\hline Treatment & Uric acid (mg/dl) & Creatinine level (mg/d) & Gain weight (\%) \\
\hline Negative control (G1) & $2.9286 \pm 0.2536^{\mathrm{a}}$ & $0.6855 \pm 0.0697^{\mathrm{a}}$ & $16.886 \pm 0.4640^{\mathrm{a}}$ \\
Positive control (G2) & $6.1402 \pm 0.5783^{\mathrm{c}}$ & $1.3966 \pm 0.04803^{\mathrm{c}}$ & $16.269 \pm 0.6496^{\mathrm{a}}$ \\
Extract of Celery 5 g/Kg (G3) & $4.2531 \pm 0.6665^{\mathrm{b}}$ & $1.2933 \pm 0.14629^{\mathrm{bc}}$ & $1.1816 \pm 0.0424^{\mathrm{bc}}$ \\
Extract of Leek 5 g/Kg (G4) & $3.4822 \pm 0.2362^{\mathrm{ab}}$ & $1.1520 \pm 0.06612^{\mathrm{bc}}$ & $17.216 \pm 1.1514^{\mathrm{a}}$ \\
Extract of Parsley 5 g/Kg (G5) & $3.5704 \pm 0.2149^{\mathrm{ab}}$ & $1.046 \pm 0.0583^{\mathrm{b}}$ & $16.736 \pm 1.1055^{\mathrm{a}}$ \\
Extract of molokhia 4.8 g/Kg (G6) & $4.1739 \pm 0.1836^{\mathrm{b}}$ & $16.851 \pm 0.49^{\mathrm{a}}$ \\
\hline
\end{tabular}

All the values are expressed as the mean \pm standard error of the mean. The mean difference is significant $(P<0.05)$ when compared with the positive control (gouty rat) group

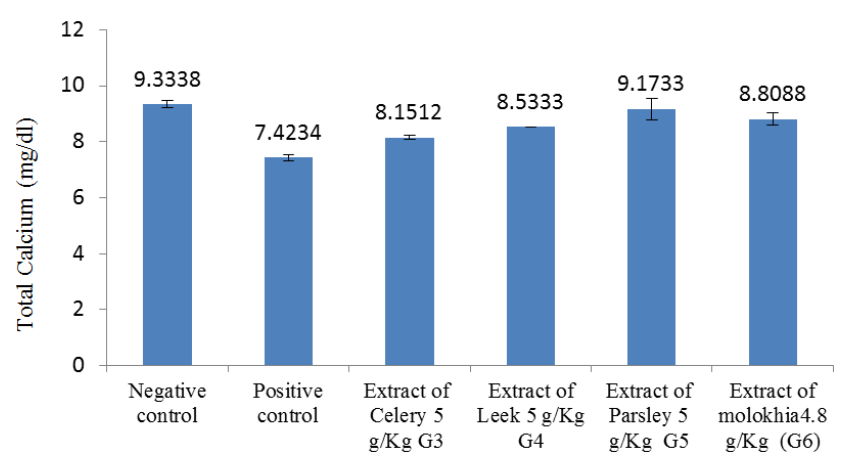

Fig. (3). Total calcium ( $\mathrm{mg} / \mathrm{dl}$ ) levels of aqueous extract of celery, leek, parsaly, and molokhia in normal and potassium oxonate-induced gout rats.

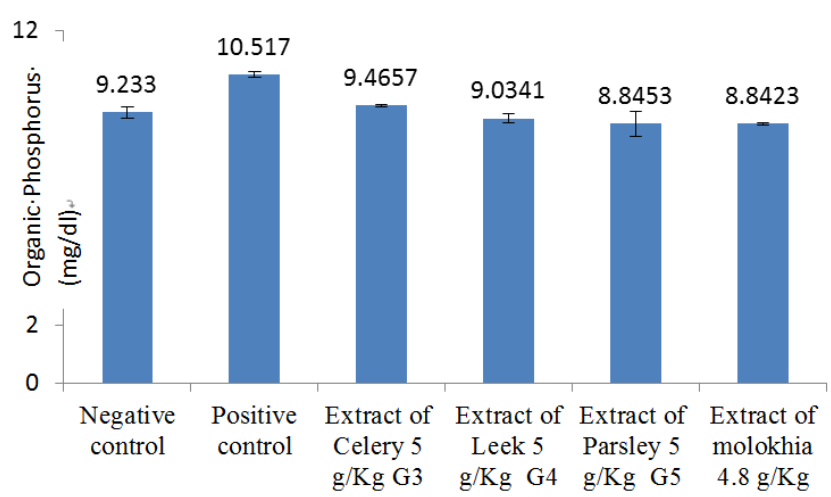

(G6)

Fig. (4). Organic Phosphorus ( $\mathrm{mg} / \mathrm{dl}$ ) levels of aqueous extract of celery, leek, parsaly, and molokhia in normal and potassium oxonate-induced gout rats.
The present study also investigated the efficacy of orally administered celery, leek, parsley, and molokhia extracts on blood biomarkers of oxidative stress (Malonaldehyde concentration) and lipid peroxidation levels in rats blood. In gouty control rats (G2), the levels of serum MDA, as a biomarker of lipid peroxidation, were statistically $(\mathrm{p} \leq 0.05)$ higher than normal rats (G1). Oral administration of celery, leek, parsley, and molokhia to gouty rats induced a significant reduction $(\mathrm{p} \leq 0.05)$ in these elevated levels of MDA, but could not yet reach these levels to the normal value G1 (Table 2). Potassium oxinate treatment increased MDA levels significantly at dose used $(250 \mathrm{mg} / \mathrm{Kg})$, reflecting the increase in lipid peroxidation. In contrast to these results, there was decrease in glutathione peroxidase (GPx) enzyme activity compared with the controls (G1). GPx enzyme activity levels were found to have increased in parsley (G5) the value was $3.0597 \mathrm{U} / \mathrm{mg}$ protein).

The effect extracts of celery, leek, parsley, and molokhia on the enzymatic antioxidant levels catalase (CAT) and superoxide dismutase (SOD) in experimental rat were tabulated in Table 2. CAT and SOD level was decreased significantly in positive control (G2) when compared to control group (G1). Administration of extracts to potassium oxonate-induced rat altered the above changes by regulating the CAT level to nearly that of normal levels. Molokhia and parsley (G5, G6) also significantly inhibited the decreased levels of MDA and increased the levels of SOD and CAT in gouty rats $(\mathrm{P}<0.05)$. 
Table 2. MDA levels and antioxidant enzyme activities of groups.

\begin{tabular}{lllll}
\hline Treatment & MDA (nmol/mL) & $\begin{array}{l}\text { Superoxide dismutase } \\
\text { (SOD) (U/mg protein) }\end{array}$ & $\begin{array}{l}\text { Catalase (CAT) (U/mg } \\
\text { protein) }\end{array}$ & GPX (U/mg protein) \\
\hline Negative control (G1) & $3.0619 \pm 0.1197^{\mathrm{a}}$ & $3.6201 \pm 0.2451^{\mathrm{ab}}$ & $10.134 \pm 0.7023^{\mathrm{a}}$ & $3.8180 \pm 0.1499^{\mathrm{a}}$ \\
Positive control (G2) & $5.2374 \pm 0.0808^{\mathrm{c}}$ & $1.9656 \pm 0.06397^{\mathrm{c}}$ & $5.9359 \pm 0.32497^{\mathrm{e}}$ & $1.0732 \pm 0.0885^{\mathrm{e}}$ \\
Extract of Celery 5 g/Kg (G3) & $4.1747 \pm 0.1528^{\mathrm{b}}$ & $3.1081 \pm 0.1924^{\mathrm{b}}$ & $7.2546 \pm 0.27389^{\mathrm{d}}$ & $2.0222 \pm 0.10558^{\mathrm{d}}$ \\
Extract of Leek 5 g/Kg (G4) & $4.0085 \pm 0.1939^{\mathrm{b}}$ & $3.3099 \pm 0.1937^{\mathrm{ab}}$ & $8.3224 \pm 0.05065^{\mathrm{c}}$ & $2.5289 \pm 0.10609^{\mathrm{c}}$ \\
Extract of Parsley 5 g/Kg G5 & $3.839 \pm 0.4286^{\mathrm{b}}$ & $3.8174 \pm 0.1169^{\mathrm{a}}$ & $9.0268 \pm 0.100796^{\mathrm{b}}$ & $3.0597 \pm 0.08822^{\mathrm{b}}$ \\
Extract of molokhia $4.8 \mathrm{~g} / \mathrm{Kg}(\mathrm{G} 6)$ & $3.5263 \pm 0.2626^{\mathrm{ab}}$ & $3.252 \pm 0.1913^{\mathrm{ab}}$ & $8.5267 \pm 0.39954^{\mathrm{bc}}$ & $1.9917 \pm 0.15365^{\mathrm{d}}$ \\
\hline
\end{tabular}

All the values are expressed as the mean \pm standard error of the mean. The mean difference is significant $(P<0.05)$ when compared with the positive control (gouty rat) group

There was a significant $(\mathrm{P}<0.05)$ increase in acid phosphatase (ACP) and alkaline phosphatase (ALP) enzyme activities in rat treated with the uricase inhibitor, potassium oxonate (G2) when compared to the normal control (G1). These were found to be reverted back in extracts of celery, leek, parsley, and molokhia treated animals. Treatment with extract of parsley significantly $(\mathrm{P}<0.05)$ decreased the ACP and ALP when compared to all extracts. On the other hand, the activity produced by extract of parsley (G5) was almost similar to that of the negative control (G1) (Table 3).

Table 3. Acid phosphatase and Alkaline phosphatase levels of groups.

\begin{tabular}{lll}
\hline Treatment & acid phosphatase (ACP) & Alkaline phosphatase (ALP) \\
\hline Negative control (G1) & $0.1108 \pm 0.1046^{\mathrm{a}}$ & $168.72 \pm 7.3169^{\mathrm{a}}$ \\
Positive control (G2) & $0.2778 \pm 0.0078^{\mathrm{c}}$ & $432.63 \pm 12.1662^{\mathrm{d}}$ \\
Extract of Celery 5 g/Kg (G3) & $0.16114 \pm 0.02044^{\mathrm{b}}$ & $292.48 \pm 5.2898^{\mathrm{c}}$ \\
Extract of Leek 5 g/Kg (G4) & $0.1915 \pm 0.00961^{\mathrm{b}}$ & $286.14 \pm 5.2285^{\mathrm{c}}$ \\
Extract of Parsley 5 g/Kg (G5) & $0.11384 \pm 0.01347^{\mathrm{a}}$ & $253.44 \pm 8.850^{\mathrm{b}}$ \\
Extract of molokhia 4.8 g/Kg (G6) & $0.1613 \pm 0.016634^{\mathrm{b}}$ & $286.24 \pm 4.2929^{\mathrm{c}}$ \\
\hline
\end{tabular}

All the values are expressed as the mean \pm standard error of the mean. The mean difference is significant $(P<0.05)$ when compared with the positive control (gouty rat) group

\section{Discussion}

One of the most sensitive and dramatic indicator of gout is neutrophil influx into the joint fluid. Neutrophils accumulate in both the joint fluid and the synovial membrane, where a small fraction of these cells actively phagocytose monosodium urate crystals and release mediators, that are chemotactic and amplify the inflammatory reaction (55). The enzyme XO catalyzes the oxidation of hypoxanthine to xanthine and then to uric acid, which plays a crucial role in gout (56). XO is an important source of oxygen derived free radicals. The enzyme catalyzes reduce oxygen (during reperfusion phase), leading to the formation of superoxide anion radicals and hydrogen peroxide, as well as hydroxyl radicals (57). It has been proposed as a central mechanism of oxidative injury in some situations like gout, ischemia, renal damage, hypertension, diabetes, etc. (58, 16 and 59). Recent findings show that the occurrence of gout is increasing worldwide, possibly due to the changes in dietary habits like intake of high-purine foods viz., organ meats, yeast, beer and other alcoholic beverages (60 and 61). The main therapeutic approach for gout is the use of XOI such as allopurinol, which block the final step in the synthesis of uric acid from purines (62 and 63). An alternative to allopurinol is the use of medicinal plants which possess phytochemical constituents. We thus began our program to look for xanthine oxidase inhibitors of phytochemical origin from the extracts of celery, leek, parsley, and molokhia. Phytochemical screening of extracts revealed the presence of flavonoids, phenolics, and saponins accounting for its antioxidant property. Flavonoids are a group of polyphenolic compounds which exhibit several biological effects such as antiinflammatory, anti-hepatotoxic, antiulcer activities, etc. Also, the structure-activity relationship of different chemical classes of flavonoids have been reported as potential inhibitors of XOD (26, 27, 33, 28, 29, 22, 32and 36). Several in-vitro studies confirmed the xanthine oxidase to Xanthine dehydrogenase (XOD/XDH) inhibitory activity of some flavonoids. These compounds are structurally similar to $\mathrm{XOD} / \mathrm{XDH}$ substrate and so can inhibit the enzyme activity (64 and 65). Celery, leek, parsley, and molokhia have also demonstrated the least XO inhibitory (XOI) activity probably due to limited bioactive compounds present. The extent of increasing in XOI activity elicited by allopurinol was much higher than that observed with the celery, leek, parsley, and molokhia in both extraction solvent. Similar results have been reported by others (66 and 39).In the present study, we noted Parsley and celery were the best source of raw material for obtaining the XOI compound as each exhibits more than $70 \%$ inhibition of XOD under all two extraction solvents. In fact, Parsley and celery under evaluation have shown considerable activity for XOD inhibition, substantiate the fact that secondary metabolites in the leaves contain diverse classes of bioactive phenolic compounds such as polyphenols, tocopherols and alkaloids (67, 68 and 32), which may act as XOI.

It is well known that XOD is an inducible enzyme. Oxonic acid and its salts are foreign substances that could interfere with some other metabolic systems in mice. It was found that oxonate was distributed to the intracellular sites of the small 
intestine at a much higher concentration after oral administration. In addition, it was converted mostly to cyanuric acid in the gastrointestinal tract partly by XOD (69). Serum urate level is partly regulated by the kidney in rodents. Physiological and pharmacological studies have suggested that urate produced in liver is transported bidirectional in the proximal tubule. As oxonate is a competitive uricase inhibitor, it is likely that oxonate similarly competes with urate for binding at a specific site within urate transporter and permit efflux of urate subsequent to its intracellular production. Further, many studies confirmed that oxonate specifically inhibited renal electrogenic urate transport, and also blocks channel activity of urate transporter in mammalian $(70,71$, and 72). The levels of uric acid, and creatinine were significantly elevated after oxonate treatment in our study. In the goutyrat, serum uric acid and creatinine levels reduced significantly after extracts of celery, leek, parsley, and molokhia administration. Similar results have been reported by others (20, 73, 74 and 75). Although the elevated levels of uric acid in the circulation could give rise to gout and possibly other pathological conditions (76), the antioxidant action of uric acid, particularly its ability to inhibit DNA damage, is also well documented (76 and 19). Parsley (Petroselinum crispum) as a dietary vegetable can be used safely long-term; this feature of parsley makes it a possible alternative for allopurinol, or at least in combination therapy to minimize the side-effects of allopurinol (39).XOD was found to be significant activity in liver. Uric acid synthesis appears to be mainly a hepatic process. Therefore, the gout effect of celery, leek, parsley, and molokhia could be explained, at least in part, by blocking of liver of XOD activities. The present study was the first account demonstrating the in vivo gout action of celery, leek, parsley, and molokhiaas well as their ability to decrease serum uric acid and creatinine levels in animals orally administered with our extracts. Duke (77) and Balch et al., (78) recorded that the seeds and stalks of celery are known to reduce uric acid levels, relieving symptoms of joint pain and immobility. In one study, Apium graveolens has shown significant reduction in serum uric acid level in rats (79). Apium graveolens is used to treat fungal infections and tumors. Apiumgraveolens contains furocoumarins that are typically prescribed for their stomachic, carminative, diuretic and emmenagogue properties (80).

Our study indicates that by increasing serum total calcium level with extracts of celery, leek, parsley, and molokhia in comparison to positive control, symptoms of gouty arthritis are reduced. While comparing of organic phosphorus levels of Group 2 (positive control) with group 1 and gouty rat groups, highly significant correlation was observed $(\mathrm{P}<$ 0.05). It was due to high organic phosphorus levels of Group G2 $(10.517 \mathrm{mg} / \mathrm{dL})$ which is the highest of all these groups. Molokhia are edible and are used as an ingredient for popular food in Egypt. This plant is also rich in potassium, calcium, phosphorous, iron, ascorbic acid, and carotene (36). Celery provides an excellent source of vitamin B1, B2, B6, C and fiber. It's a very good source of folic acid, potassium, and calcium (81 and 82). Leeks are a good source of dietary fiber, folic acid, calcium, potassium, and vitamin C. Calcium in leeks is also used for the proper clotting of blood in the human body ( 83 and 84 ).

In recent years, there is increasing interest in free radicals; they have been shown to modify biological molecules, which may result in various pathological conditions. Thus additional natural products need to be evaluated for their antioxidant potential. Considerable evidence suggests that oxidative stress and reactive oxygen species (ROS) play significant roles in several aspects of acute and chronic inflammation (85). The increased lipid peroxide level noticed in potassium oxonate induced rat in our study (Group 2), due to its release from neutrophils and monocytes during inflammation (86). The result of the present study indicate that the antioxidant defense system is compromised in potassium oxante induced rat as evidenced by increased lipid peroxidation concentration and decreased activity of antioxidant enzyme. Our results show that the activities of Superoxide dismutase, Glutathione peroxidase and Catalase decreasing in potassium oxonate-induced animals which may be due to consequence of their increased consumption during oxidative stress and cellular lysis. All extracts of celery, leek, parsley, and molokhiahave shown significant decrease in level of MDA and increase in activity of antioxidant enzyme level, comparable to positive rat (G2). Thereby revealing that serum uric acid through lipid peroxidation, might be working towards the etiopathogenesis of oxidative stress diseases and its serum level may be a deciding factor for progression of the disease, and also our study showed that parsley (Petroselinum crispum) has a higher potential than celery, leek, and molokhia to increase glutathione peroxidase activity. Several studies have identified the active antioxidants within parsley (Petroselinum crispum) including flavonoids (32), carotenoids (87), ascorbic acid (88), tocopherol and coumarines (32). These phytochemicals improve total antioxidant capacity, suppress destructive oxygen free radicals and prevents oxidative stress damage (75 and 89). This was in agreement with Haidari et al., (39). Leeks are a good source of allyl sulfides and also rich in the flavonoid especially kaempferol. Allyl derivatives of leek oils stimulate the activity of $\mathrm{GP}_{\mathrm{X}}$ and inhibited the decreased ratio of reduced to oxidized glutathione produced by $12-O$ tetradecanoylphorbol-13- acetate in epidermal cells. Diallyldisulfide increase $\mathrm{GP}_{\mathrm{X}}$ activity in animal tissues with increased the activity of glutathione reductase, and superoxide dismutase $(90,84$ and 91). A phenolic extract of molokhia exhibited antioxidant activity through the radical generator-initiated peroxidation of linoleic acid (36). Al Batran et al., (92) showed that gastroprotective effect of an ethanolic extract of molokhia against ethanol-induced gastric ulcers in adult Sprague Dawley rats. SOD and MDA levels were significantly increased $(P \leq 0.05)$ and reduced $(P$ $\leq 0.05)$, respectively pretreatment with molokhia. Oyedeji and Bolarinwa (93) found that aqueous extract of molokhia has beneficial potentialities on the blood chemistry of male albino rats. As in traditional medicine they were used for 
management of gout it is thought that their anti-gout activity, at least by part, was related to this xanthine oxidase inhibitory activity. Gouty arthritis is metablic disorder that is characterized by deposition of uric acid into joints (94). Now there is new trend to use herbal medicine because of their potential to cure and fewer or no side effects. Medicinal plants having anti-inflammatory, uricosuric and xanthine oxidase inhibitory activities are used in gouty arthritis. Herbal medicines are comparably safe, and are useful in the management of gout. Although allopurinol is commonly used in the treatment of gouty arthritis but this has side effects such as skin rashes, nauseas and vomiting. The possible explanation can be drawn from number of studies showing that superoxide dismutase during catalyzing dismutation of $\mathrm{O}_{2}$ to $\mathrm{H}_{2} \mathrm{O}_{2}$ can form copper bound hydroxyl radical from hydrogen peroxide $\mathrm{H}_{2} \mathrm{O}_{2}$ (95). Hydroxyl radical when gets bounded to SOD, then it can attack adjacent histidine residue which is attached to copper resulting in inactivation of both SOD1 and SOD3 (96).

Conclusion, this study had established the xanthine inhibitory action of several plant extracts used in Egypt folk medicine. The extracts of celery, leek, parsley, and molokhia have been tested for xanthine oxidase inhibitory activity. The efficacy of distilled water as the extraction solvents was commendable because most of the plants used to treat gout were administered as decoctions and infusions, so the biologically active compounds were most likely watersoluble. In addition, the possibility of any harmful residue due to use of organic solvent was also avoided. The selection of tropical plants used in medicine and screening of their extracts for pharmacological activity may provide identification of newer medicaments for the treatment of various ailments especially gout. Further research on celery, leek, parsley, and molokhia have significantly reduced the serum uric acid, lipid peroxidation, and increase activity of antioxidant enzyme levels in gouty rats. This may be due to the inhibition of $\mathrm{XO}$ activity and the presence of phytochemical constituents.

\section{Acknowledgements}

The authors are thankful to Prof. Dr. Hanaa Sidky Special Food and Nutrition Dept., Food Technology Research Institute, Agricultural Research Center, for valuable helping in this study.

\section{References}

[1] Singh, H.; Krishna, G. and Baske, P.K.(2010). Plants used in the treatment of joint diseases (rheumatism, arthritis, gout and lumbago) in Mayurbhanj district of Odisha, India. Rep. Opin. 2: $22-26$.

[2] Falasca, G.F. (2006). Metabolic diseases: gout. Clin. Dermatol24:498-508.

[3] Haidari, F.; Rashidi, M. R.; Keshavarz, S. A.; Mahboob, S. A.; Eshraghian, M. R. and Shahi, M. M. (2008).Effects of onion on serum uricacid levels and hepatic xanthine dehydrogenase/xanthineoxidase activities in hyperuricemic rats. Pak J Biol Sci. 11: 1779-84.

[4] Dalbeth, N. and Haskard, D. O. (2005).Mechanisms of inflammation in gout. Rheumatology 44: 1090-1096.

[5] Corrado, A.; D'Onofrio, F.; Santoro, N.; Melillo, N. and Cantatore, F. P. (2006).Pathogenesis, clinical findings and management of acute and chronic gout. Minerva Med. 97: 495-509.

[6] Bieber, J. D. and Terkeltaub, R. A. (2004).Gout on the Brink of Novel Therapeutic Options for an Ancient Disease.Arthritis \& rheumatism 50 (8): 2400-2414.

[7] González, A. G.; Bazzocchi, I. L.; Moujir, L.; Ravelo, A. G.; Correa, M. D. and Gupta, M. P. (1995). Xanthine oxidase inhibitory activity of some Panamanian plants from celastraceae and lamiaceae. The Journal of Ethnopharmacology 46 (1): 25-29.

[8] Ramallo, I. A., Zacchino, S. A. and Furlan, R. L. E. (2006).A rapid TLC autographic method for the detection of xanthine oxidase inhibitors and superoxide scavengers. Phytochemical Analysis 17 (1): 15-19.

[9] Moriwaki, Y. (2014).Effects on Uric Acid Metabolism of the Drugs except the Antihy peruricemics. J. Bioequiv Availab. 6 (1):10-17.

[10] Nile, S. H. and Khobragade, C. N. (2011).In-vitro antiinflammatory and xanthine oxidase inhibitory activity of Tephrosia purpurea L. shoot extract. Nat. Product Comm. 6: 1437-1440.

[11] Battelli, M. G.; Corte, E. D. and Stirpe, F. (1972). Xanthine oxidase type D (dehydrogenase) in the intestine and other organs of the rat. Biochemical Journal 126 (3):747-749.

[12] Unno, T.; Sugimoto, A. and Kakuda, T. (2004).Xanthine oxidase inhibitors from the leaves of Lagerstroemia speciosa (L.) Pers. J Ethnopharmacol 93:391-5.

[13] Sweeney, A.P.; Wyllie, S.G.; Shalliker, R.A. and Markham, J.L.(2001).Xanthine oxidase inhibitory activity of selected Australian native plants.J. Ethnopharmacol. 75: 273-277.

[14] Kong, L. D.; Abliz, Z.; Zhou, C. X.; Li, L. J.; Cheng, C. H. K. and Tan, R. X. (2001).Glycosides and xanthine oxidaseinhibitors from Conyza bonariensis. Phytochemistry 58 (4): 645-651.

[15] Umamaheswari, M.; Asok Kumar, K.; Somasundaram, A.; Sivashanmugam, T.; Subhadradevi, V. and Ravi, T. K. (2007).Xanthine oxidase inhibitory activity of someIndian medicinal plants. Journal of Ethnopharmacology 109 (3): $547-551$.

[16] Berry, C. E. and Hare, J. M. (2004).Xanthine oxidoreductase and cardiovascular disease: Molecular mechanisms and pathophysiological implications. J. Physiol. 555: 589-606.

[17] Nguyen, M. T. T.; Awale, S.; Tezuka, Y.; Tran, Q.L.; Watanabe, H. and Kadota, S. (2004)Xnthine oxidase inhibitory activity of Vietnames medicinal plants. Biol. Pharm. Bull. 27: 1414-1421.

[18] Strazzullo, P. and Puig, J.G. (2007).Uric acid and oxidative stress: Relative impact on cardiovascular risk. Nutr.Metab.Cardiovasc. Dis. 17: 409-414. 
[19] Wang, Y.; Zhu, J. X.; Kong, L. D. Yang, C.; Cheng, C. H. and Zhang, $X$. (2004).Administration of procyanidins from grape seeds reduces serumuric acid levels and decreases hepatic xanthine dehydrogenase/oxidase activities in oxonate-treated mice. Basic Clin Pharmacol Toxicol. 94: 232-7.

[20] Kong, L. D.; Yang, C.; Ge, F.; Wang, H. D. and Song, G. Y.(2004). A Chinese herbal medicine Ermiao wan reduces serum uric acid level and inhibits liver xanthine dehydrogenase and xanthine oxidase in mice. $J$. Ethnopharmacol. 93: 325-330.

[21] Abd Aziz, S. M.; Low, C. N.; Chai, L. C.; Abd Razak, S. S. N.; Selamat, J.; Son, R.; Sarker, M. Z. I. and Khatib, A. (2011).Screening of selected Malaysian plants against several food borne pathogen bacteria. International Food Research Journal 18(3)1195-1201.

[22] Costantino, L.; Albasini, A.; Rastelli, G. and Benvenuti, S. (1992). Activity of polyphenolic crude extracts as scavengers of superoxide radicals and inhibitors of xanthine oxidase. Planta Medica 58: 342-344.

[23] Chang, W. S.; Lee, Y. J.; Lu, F. J. and Chiang, H. C. (1993).Inhibitory effects of flavonoids on xanthine oxidase.Anticancer Research 13: 2165-2170.

[24] Selloum, L.; Reichl, S.; Muller, M.; Sebihi, L. and Arnhold, J. (2001).Effects of flavonols on the generation of superoxide anion radicals by xanthine oxidase and stimulated neutrophils. Archives of Biochemistry and Biophysics 395 (1): 49-56.

[25] Chang, W. S. and Chiang, H. C. (1995).Structure activity of coumarins in xanthine oxidase inhibition. Anticancer Research 15: 1969-1974.

[26] Cheung, M.C.; Lin, L. Y.; Yu, T. H. and Peng, R. Y. (2008).Hypolipidemic and antioxidant activity of mountian celery seed essential oils. J Agric Food Chem. 56 (11): $3997-$ 4003.

[27] Tsi, D.; Das, N.P. and Tan, B. K. (1995). Effects of aqueous celery (Apium graveolens) extract on lipid parameters of rats fed a high fat diet. Planta Med. 61: 18-21.

[28] Onyeagba, R. A.; Ugbogu, O. C.; Okeke, C. U AndIroakasi, O. (2004). Studies On TheAntimicrobial Effects Of Garlic (Allium SativumLinn), Ginger (Zingiber Officinale Roscoe) AndLime (Citrus Aurantifolia Linn). Afr.J.Biotechnol. 3:552-554.

[29] Garth, L. N. And Rita, E. (2006). LipidReplacement And Antioxidant NutritionalTherapy For Restoring Mitochondrial FunctionAnd Reducing Fatigue In Chronic Fatigue Syndrome And Other Fatiguing Illnesses. Journal Of Chronic Fatigue Syndrome 13(1): 57-68.

[30] Lopez, M. G.; Sanchez-Mendoza, I. R. and Ochoa-Alejo, N.(1999). Compartive study of volatile components and fatty acids of plants and in-vitro cultures of parsley Petroselinum crispum (Mill) nym ex hill. J. Agric. Food Chem. 47: 32923296.

[31] Ozsoy-Sacan O, Yanardag R, Orak H, Ozgey Y, Yarat A and Tunali T.(2006).Effects of parsley (Petroselinum crispum) extract versus glibornuride on the liver of streptozotocininduced diabetic rats. J. Ethnopharmacol. 104: 175-181.

[32] Fejes, S. Z.; Blazovics, A.; Lemberkovics, E.; Petri, G.; Szoke, E. and Kery, A.(2000).Free radical scavenging and membrane protective effects of methanol extracts from Anthriscus cerefolium (Hoffm) L. and Petroselinum
crispum(Mill) Nym. Ex A. W. Hill. Phytother. Res. 14: 362365 .

[33] Peterson, S.; Lampe, J.W.; Bammler, T. K.; Gross-Steinmeyer, K. and Eaton, D. L. (2006).Apiaceous vegetable constituents inhibit human cytochrome P-450 1A2 (hCYP1A2) activity and hCYP1A2-mediated mutagenicity of aflatoxin $\mathrm{B}_{1}$. Food Chem. Toxicol. 44: 1474-1484.

[34] Zeghichi, S.; Kallithkara, S. and Simopoulus, A. P. (2003).Nutritional composition of Molokhia (Corchorus olitorius) and Stammagathi (Cichorium spinosum) in plants, in human health and nutritional policy. Simopoulus, A. P and C. Gopalan (Eds.) Karger, Basel, pp 1-21.

[35] Abu- Hadid, A. F.; El-Shinawy, M. Z.; El-Bethagy, A. S.; Gaafer, S. A.; Medany, M. (1994).Studies on the production of off-season Jew's mallow (Molokhia) in Egypt. Egypt J. Hort. 21:187-193.

[36] Azuma, K.; Nakayama, M.; Koshioka, M.; Ippoushi, K.; Yamaguchi, Y.; Kohara, K.; Yamauchi, Y.; Ito, H. and Higashio, H.(1999).Phenolic antioxidants from the leaves of Corchorus olitorius L. Journal of Agricultural and Food Chemistry 47, 3963-3966.

[37] Harborne, J. B. (1998). Phytochemical methods: A guide to modern technique of plant analysis, 3rd edn. London: Chapmann \& Hall.

[38] Naseem, S. A.; Muhammad, F.; Muzammil, H. N.; Kouser, B. M. and Aurangzeb, H. (2006). Activity of polyphenolic plant extracts as scavengers of free radicals and inhibitors of xanthine oxidase. The Journal of Basic and Applied Sciences 2 (1).

[39] Haidari, F.; Keshavarz, S. A.; Shahi, M. M.; Mahboob, S. A.and Rashidi, M. (2011).Effects of Parsley (Petroselinum crispum) and its Flavonol Constituents, Kaempferol and Quercetin, on Serum Uric Acid Levels, Biomarkers of Oxidative Stress and Liver Xanthine Oxidoreductase Aactivity in Oxonate-Induced Hyperuricemic Rats.Iranian Journal of Pharmaceutical Research 10 (4): 811-819.

[40] Das, A. K.; Bag, S.; Sahu, R.; Dua, T. K.; Sinha, M. K.; Gangopadhyay, M.; Zaman, K. and Dewanjee, S. (2010). Protective effect of Corchorus olitorius leaves on sodium arsenite-induced toxicity in experimental rats. Food and Chemical Toxicology 48:326-335.

[41] Mahgoub, S., El-Sharkawi, F. \& Badary, O. (2007) Effect of Molokhia soup on blood sugar, hepatic antioxidant status \& plasma lipid profile in diabetic rats. The Egyptian journal of biochemistry \& molecular biology (EJBMB), 25, 305-325.

[42] Hall, I. H.; Scoville, J. P.; Reynolds, D. J.; Simlot, R. and Duncan, P. (1990). Substituted cyclic imides as potential antigout agents.Life Sci. 46: 1923-1927.

[43] Ledwozyw A, Michalak J,.Stepien A, Kadziolka A.(1986). The relationship between plasma triglycerides,cholesterol, total lipids and lipid peroxidationproducts during human atherosclerosis. Clin. Chim. Acta 155: 275-284.

[44] Marklund, S.L. and Marklund, G. (1974) Involvement ofsuperoxide anion radical in the autoxidation ofpyrogallol and a convenient assay for superoxidedismutase. Eur. J. Biochem,; 47: 469-474.

[45] Sinha, A. K. (1972) Colorimetric assay of Catalase. Anal. Biochem 47: 389-394. 
[46] Rotruk, J. T.; Pope, A. L.; Ganther, H. E.; Swanson, A. B.; Hafeman, D. G. and Hekstra, W. G.(1973). Selenium, biochemical role as a component of glutathioneperoxidase purification and assay. Science 179: 588-590.

[47] King, J. (1965). The hydrolases-acid and alkalinephosphatases, In: Van D (ed), Practical clinicalenzymology, Nostrand Company Limited, London, pp, 191-208.

[48] Varley, H.; Gewenlock, A. and Bell, M. (1980).Practical Clinical Biochemistry. Vol. 1. 5th edn, pp. 741, 897. London: William Heinemen Medical. Books, Ltd.

[49] Larsen, K. (1972).Creatinine assay by a reaction kinetic principle.Clin.Chem. Acta. 41: 209-213.

[50] Caraway, W. T. (1955).Determination of uric acid in serum by a carbonate method Amer. J. of Clin. Pathology2: 840-845.

[51] Lowry, O. H.; Rosebrough, N. J.; Farr, A. I and Randall, R. J.(1951).Protein measurement with the folin phenolreagent. $J$. Biol. Chem 193: 265-275.

[52] Ferguson, E.; Vaughan, A. and Swale, J.(1976). A method for the estimation of total calcium in serum or heparinized plasma. Clinica Chimica Acta 67(3): 281-286.

[53] Fiske C. H. and Subbarow Y. (1925). The colorimetric determination of phosphorus. J Biol Chem 66:375-400.

[54] Snedecor, G. W. and Cochran, W.G. (1980).Statistical methods Book, p420, 7th Ed Iowa Stat Univ. Press, Ames, Iowa, USA.

[55] Landis, R. C. and Haskard, D. O. (2001). Pathogenesis of crystalinduced inflammation. Curr Rheumatol Rep. 3:36-41.

[56] Bowman, W. C. and Rand, M. J.(1980).Text book of pharmacology, 2nd ed. Blackwell, Sydney 243-244.

[57] Halliwell, B.and Gutteridge, J. M. C. (2001). Free radicals in biology and medicine, 3rd ed. Oxford University press, Oxford 28-30.

[58] Mazzali, M.; Hughes, J.; Kim, Y.; Jefferson, J.A.; Kang, D. and Gordon, K.L. (2001). Elevated uric acid increases blood pressure in the rat by a novel crystal-independent mechanism. Hypertension. 38, 1101-1106.

[59] Nakagawa, T; Mazzali, M.; Kang, D.; Sanchez-Lozada, L. G.; Herrera-Acosta, J. and Johnson, R.J. (2006).Uric acid - a uremic toxin? Blood. Purif. 24, 67-70.

[60] Choi, J. W. and Ford,E. S. (2008).Sugar Sweetened Soft Drinks, Diet Soft Drinks, and Serum Uric Acid Level: The Third National Health and Nutrition Examination Survey," $\mathrm{Ar}$ - thritis \& Rheumatism 59 (1): 109-116.

[61] Mayes, P. A. (1993).Intermediary Metabolism of Fructose," Ame- rican Journal of Clinical Nutrition 58 (5): 754S-765S.

[62] Kumar, A.; Edward, N.; White, M. I.; Johnston, P.W. and Catto, G. R.(1996).Allopurinol, erythema multiforme and renal insufficiency. BMJ. 312, 173-174.

[63] Wallach, S.L. (1998).The side effects of allopurinol. Hosp. Pract. 33, 22.

[64] Mo, S. F.; Zhou, F.; Lv, Y. Z.; Hu, Q. H.; Zhang, D. M. and Kong, L. D. (2007). Hypouricemic action of selected flavonoids in mice: structure-activity relationships. Biol. Pharm. Bull. 30: 1551-1556.
[65] Lin, C. M.; Chen, C. S.;Chen, C. T.; Liang, Y. C. and Lin, J. K. (2002).Molecular modeling of flavonoids that inhibits XO. Biochem. Biophys. Res. Commun. 294: 167-172.

[66] Azmi, S. M. N.; Jamal, P. and Amid, A. (2012).Xanthine oxidase inhibitory activity from potential Malaysian medicinal plant as remedies for gout.International Food Research Journal 19(1): 159-165.

[67] Zhou, K. and Yu, L.(2006).Total phenolic contents and antioxidant properties of commonly consumed vegetables grown in Colorado.Food Sci. Technol. 39, 1155-1162.

[68] Halliwell, B.; Gutteridge, J. M. C.; FreeSreeramulu, D. and Raghunath, M. (2010). Antioxidant activity and phenolic content of roots, tubers and vegetables commonly consumed in India. Food Res 43, 1017-1020.

[69] Yoshisue, K.; Masuda, H.; Matsushima, E.; Ikeda, K.; Nagayama, S. and Kawaguchi, Y. (2000). Tissue distribution and biotransformation of potassium oxonate after oral administration of a novel antitumor agent (drug combination of tegafur, 5-chloro-2, 4-dihydroxypyridine, and potassium oxonate) to rats. Drug Metabolism and Disposition 28, 1162 1167.

[70] Leal-Pinto, E.; Cohen, B. E.; Lipkowitz, M. S. and Abramson, R.G. (2002).Functional analysis and molecular model of the human urate transporter/ channel, hUAT. The American Journal of Physiology -Renal Physiology 283, F150-F163.

[71] Hosoyamada, M.; Ichida, K.; Enomoto, A.; Hosoya, T. and Endou, H.(2004).Function and localization of urate transporter 1 in mouse kidney.Journalof the American Society of Nephrology 15, 261-268.

[72] Lipkowitz, M. S.; Leal-Pinto, E.; Cohen, B. E. and Abramson, R. G.(2004). Galectin9 is the sugar-regulated urate transporter/channel UAT. Glycoconjugate Journal 19, 491498.

[73] Zhao, X.; Zhu, J.X.; Mo, S.F.; Pan, Y. and Kong, L.D. (2006). Effects of cassia oil on serum and hepatic uric acid levels in oxonate-induced mice and xanthine dehydrogenase and xanthine oxidase activities in mouse liver. J. Ethnopharmacol. 103: $357-365$.

[74] Zhu, J.X.; Wang, Y.; Kong, L.D.; Yang, C. and Zhang, X. (2004).Effects of Biota orientalis extract an dits flavonoid constituents, quercetin and rutin on serum uric acid levels in oxonate-induced mice and xanthine dehydrogenase and xanthine oxidase activities in mouse liver. J. Ethnopharmacol. 93: 133-140.

[75] Neguyen, M. T. T.; Awale, S.; Tezuka, Y.; Shi, L.; Zaidi, S. F. H. and Ueda, J. (2005). Hypouricemic effects of acacetin and 4, 5-O-dicaffeoylquinic acid methyl ester on serum uric acid levels in potassium oxonate-pretreated rats. Biol. Pharm. Bull. 28: 2231-2234.

[76] Nuki G.(2006). Gout. Medicine 34: 417-423.

[77] Duke, J. A. (1997).The Green Pharmacy. Rodale Press, Pennsylvania.

[78] Balch, C. N. C.; James, F. and Phyllis, A. (1997).Prescription for Nutritional Healing. Avery Publishing Group, New York.

[79] Doha, S. (2008). Evaluation of anti-gout activity of some plant food extracts. Polish J. of Food and Nutr. Sci.,58: 389395. 
[80] Nehal, M. A. (2011). Hepatoprotective effect of feeding celery leaves mixed with Chicory leaves and barley grains to hypercholesterolemic rats. Pharmacog.Magaz.,7: 151-156.

[81] Ang, J. F. and Miller, W.B. (1991).Multiple functions of powdered cellulose as a food ingredient.Cereal Foods World $36,558-564$.

[82] Thebaudin, J. Y.; Lefobvre, A. C.; Harrington, M. and Bourgeois, C. M.(1997). Dietary fibers: Nutritional and technological interest. Trends in Food Science and Technology 8, 41-48.

[83] Dorant, E.; Van Den, P. A. and Goldbohm, R. A. (1996). A Prospective Cohort Study On The Relationship Between Onion And Leek Consumption, Garlic Supplement Use And The Risk Of Colorectal Carcinoma In The Netherlands. Carcinogenesis Mar 17(3):477-84.

[84] Riley, D. M.; Bianchini, F. and Vainio, H.(2001). Allium Vegetables And Organosulfur Compounds: Do They Help Prevent Cancer. Environ Health Perspect. Sep 109(9):893902.

[85] Ramprasad, V. R.; Shanthi, P. and Sachdanandam, P. (2005). Evaluation of antioxidant effect of Semecarpus anacardium Linn.nut extract on the components of immune system in adjuvant arthritis. Vasc. Pharmacol. 42: 179-186.

[86] Sabina, E. P.; Chandel, S. and Rasool, M. Kh. (2008). Inhibition of Monosodium Urate Crystal-Induced Inflammation by Withaferin A. J Pharm Pharmaceut Sci. 11 (4): 46-55.

[87] Francis, G. W. and Isaksen, M. (1989).Droplet counter current chromatography of the carotenoids of parsley Petroselinum crispum. Chromatographia 27: 549-551.

[88] Davey, M. W.; Bauw, G. and Montagu, M. V.(1996).Analysis of ascorbate in plant tissues by high performance capillary zone electrophoresis. Anal. Biochem. 239: 8-19.
[89] Vijayalakshmi, B. and Chandrasekhar, M. (2008). Oxidative stress and their resultant products as the target molecules in clinical diagnosis of age related disease. Curr. Trends Biotechnol. Pharm. 2: 239-250.

[90] Jin, L. and Baillie, T.A. (1997). Metabolism Of The Chemoprotective Agent Diallyl Sulfide To Glutathione Conjugates In Rats. Chem Res Toxicol 10:318-327.

[91] Al Hamedan, W. A and Anfenan, M. L. Kh. (2011).Antioxidant Activity of Leek towards Free Radical Resulting from Consumption of Carbonated Meat in Rats.Life Science Journal 8 (1): 169-176.

[92] Al Batran, R.; Al-Bayaty, F.; Abdulla, M. A.; Al-Obaidi, M. M. J.; Hajrezaei, M.; Hassandarvish, P.; Fouad, M.; Golbabapour, S. and Talaee, S. (2013). Gastroprotective effects of Corchorus olitorius leaf extract against ethanolinduced gastric mucosal hemorrhagic lesions in rats. Journal of Gastroenterology and Hepatology 28: 1321-1329

[93] Oyedeji, K. O. and Bolarinwa, A. F. (2013).Effect of Corchorus Olitorius Extract On Haematological and Plasma Biochemical Parameters in Male Albino Rats.Journal of Dental and Medical Sciences 3(5):68-71.

[94] Terkeltaub, R. (2010). Gout: Novel therapies for treatment of gout and hyperuricemia, Arthritis Research andTher., 11: 234236.

[95] Hink, H. U.; Santanam, N.; Dikalov, S.; Mc Cann, L.; Nguyen, A. D.; Parthasarathy, S.; Harrison, D. G. and Fukai,T. (2002).Peroxidase Properties of Extracellular Superoxide Dismutase. Role of Uric Acid in Modulating in Vivo Activity," Arteriosclerosis, Thrombosis, and Vascular Biology 22(9):1506-1508.

[96] Jewett,S. L.; Rocklin, A. M.; Ghanevati, M.; Abel, J. M. and Marach, J. A.(1999).A New Look at a Time-Worn System: Oxidation of CuZn-SOD by $\mathrm{H}_{2} \mathrm{O}_{2}$. Free Radical Biology \& Medicine 26 (7-8): 905-918. 